\title{
Ultrasound Follow-up Of Adhesions After One-Step Laparoscopic Abomasopexy for Correction of Left Displaced Abomasum in Cattle
}

\author{
$\odot$ Göksen Çeçen Ayalp ${ }^{1}, \oplus$ İsmail Altuğ Şen ${ }^{1,}$ \\ ๑ Nihal Yaşar Gül Satar ${ }^{1}, \oplus$ Sibel Tokoğlu Sert ${ }^{1}$
}

1Uludag University, Faculty of Veterinary Medicine, Department of Surgery, Bursa, Turkey

Received 2019-06-13 Accepted 2019-11-11

\begin{abstract}
The objective of this study was to evaluate the use of ultrasonography on the determination of the thickness of adhesion formation at the abomasopexy site in cows which had undergone one-step laparoscopic abomasopexy. Ten Holstein cows with left displaced abomasum (LDA) were included in the study. Animals were treated with one-step laparoscopic abomasopexy whilst standing. Postoperative ultrasonographic examinations were carried out starting immediately after surgery (day 0), and on days 28,90 and 120 by using a $5 \mathrm{MHz}$ linear transducer. The thickness of the adhesion formation was measured between the abdominal wall and the abomasum. Ultrasonographic image revealed the area of fixation on day 0 as a mild distorted subcutaneous tissue. A heterogeneous hypoechoic irregular-shaped mass (adhesion) was observed between the abomasum and abdominal wall on days 28,90 and 120 . Average thickness significantly $(\mathrm{p}<0.05)$ increased from day 0 to day 28 , but tended to decrease afterwards. The average thickness at the abomasopexy site was recorded as 20.47, 22.82, 22.34 and $21.92 \mathrm{~mm}$ on days $0,28,90$ and 120 , respectively.

Ultrasonographic examination can diagnose and measure adhesions between the abomasum and the abdominal wall. During the study period, adhesion formation was followed up to the 120th day, and in this period the thickness of the adhesion tended to decrease. Long follow-up studies are thought to be beneficial to determine the difference in adhesion thickness.
\end{abstract}

Keywords: LDA, one-step laparoscopic abomasopexy, ultrasound, adhesions, cattle

\section{Introduction}

In recent years, laparoscopic abomasopexy (LA) techniques have gained an acceptance for correction of left displacement of the abomasum (LDA). The LA technique combines the minimal invasiveness and visual control for abomasal positioning and fixation offered by haparoscopy. ${ }^{4,11}$ Janowitz (1998), described a two-step laparoscopically guided toggle pin (TP) fixation technique for LDA. The one-step procedure developed by Christiansen (2004) and Barisani (2004) involves placement of the TP suture within the abomasal lumen under laparoscopic guidance via the left paralumbar area in a standing cow. The other one-step procedures are performed via the ventral

* Corresponding author: Göksen Çeçen Ayalp, Adress: Uludag University, Faculty of Veterinary Medicine, Department of Surgery, 16059 Nilüfer, Bursa, Turkey. Telephone number: +90 2242940840 E-mail: goksenc@uludag.edu.tr abdominal wall with the animal positioned in dorsal recumbency. ${ }^{2,13}$

The advantages of one-step LA technique include confirmation of the LDA and the ability to evaluate adhesions between the abomasum and the left body wall or rumen. Furthermore, this technique can also be performed completely in a standing cow, is procedurally simpler, and requires less time compared with the two-step LA procedure. ${ }^{14}$

The success of these techniques depends on developing inflammatory adhesions in the abomasal fixation region and these adhesions prevent recurrence of $\mathrm{AD}$ during the 
current and the subsequent lactation. ${ }^{3,9}$ The degree and persistence of adhesions formed after correction of LDA using the laparoscopic TP suture techniques and especially traditional laparotomy techniques are poorly characterized. ${ }^{14}$ The strength and size of adhesions required of prilocaine hydrochloride (Citanest ${ }^{\circ}$, Astra Zeneca PLC) to prevent recurrence after LA is unknown and further was infiltrated locally at the points of entry for the trocar/ research is required to address this issue., ${ }^{3,14}$ A few cannula units.

authors have reported follow-up data for the assessment of

adhesions of the abomasum to the body wall after Surgery was performed in the standing animal. Standard laparoscopic abomasopexy. ${ }^{1,3,18}$ The presence or absence of equipment was used (Dr. Fritz GmbH, Germany). The first adhesions, as well as their appearance at the site of the incision was made in the left paralumbar fossa behind the abomasopexy, were confirmed by laparoscopic visualization ribs and beneath the transverse processes and a trocar was or necropsy findings. ${ }^{3,18}$ The authors have reported repeat inserted into the abdominal cavity (portal site 1). Pneumolaparoscopy 90 days after surgery found strong adhesions peritoneum was obtained and the abdominal cavity was between the abomasum and body wall in all ten cows explored. For the second portal, the incision was made positioning the cow in dorsal recumbency. on the dorsal part of the $11^{\text {th }}$ intercostal space. Next a troFurthermore, strong adhesions were observed in four car-cannula unit was inserted in the $11^{\text {th }}$ intercostal space cows that underwent repeat laparotomy 1 year after LA. ${ }^{3}$ under laparoscopic guidance. The long trocar was used for the placement of the toggle and for emptying the air from

Ultrasonography, as a diagnostic imaging technique, the abomasum. A stainless steel toggle pin with 2 lengths provides reliable information concerning the abomasum of polyamide suture (synthetic pseudo-monofilament and its contents, and the condition of its wall enables non-absorbable suture; Kruuse Supramid, USP 3+4) atidenti-fication and assessment of any changes in adjacent tached at its midpoint was inserted via the cannula into the structures. ${ }^{5,15}$ It is possible to measure the size of fibrinous abomasal lumen while the excess suture material remained adhesions between the abomasum and the abdominal exterior to the abdomen. The abomasum was deflated, and wall via ultrasonographic examination. ${ }^{1}$ In only one study, the excess suture material through with a long spieker were ul-trasonography was performed for the follow-up of pushed down into the abdominal cavity and the needle was adhe-sions in the postoperative period of two-step LA. ${ }^{1}$ To passed through the ventral aspect of the right abdominal our knowledge, there is no other study in the literature wall and the threads were pulled. The two threads we re about ultrasound follow-up of adhesions after one-step passed through a rubber bottle cap and then knotted toLA for correction of LDA.

The goal of this study was to evaluate adhesion plus, USP 2, Braun Aesculap, Tuttlingen) material. formation and measure adhesion thickness at the fixation area by using ultrasonography in a 4-month follow-up In the postoperative period, the cows received ceftiofur after one-step LA procedure for correction of LDA in the hydrochloride (Excenel ${ }^{\oplus}$, Zoetis Inc., $1.1 \mathrm{mg} / \mathrm{kg}$ standing cow.

\section{Materials and Methods}

This study plan was approved by Local Ethics with other cows. However, their feeding was kept under Committee of Uludag University (Decision no: control the day after surgery. All cows were fed with half 2014-13/03). Ten Holstein cows with LDA were used for rations for the first three post-operative days and the this study. Each animal was subjected to a general physical following days were gradually increased. Full ration examination and special examination of the was started 7 days after surgery. Clinical follow-up of gastrointestinal system. The day prior to surgery, cows the animals was done on days 0,28 , 90, and 120. Skin were examined transabdominally with ultrasound on sutures on the left abdomen were removed on day 14 . the left side of the abdomen and was mainly focused on Fixation sutures were not removed.

the examination of abomasal position and for the For the postoperative ultrasonographic examination, presence of adhesions. Ultrasonographic examinations the abomasum fixation area was investigated in were performed on non-sedated, standing cows using a transverse and longitudinal directions by using a $5 \mathrm{MHz}$ 5.0 MHz linear transducer (Mindray Z6 Vet, Turkey).

Animals were treated with one-step laparoscopic abolinear probe (Mindray Z6 Vet, Turkey) in each case on days $0,28,90$, 
and 120 . The abomasum, its contents and the condition of its wall and the adhesion formation were evaluated and the thickness of the adhesion was measured between the abdominal wall and the abomasal wall.

Statistical Analysis: Data were analyzed by the GLM procedure. Model was specified as full factorial and polynomial. Post Hoc Multiple Comparison was chosen by Tukey HSD Test. Bonferroni was chosen as certainty at interval adjustment. Differences were considered significant at a probability level of $\mathrm{p}<0.05$ in all analyses. All statistical analysis was performed with SPSS software (version 23.0, SPSS Inc, USA) statistical program. The continuous values were given as mean \pm standard deviation (SD).

\section{Results}

The cows with LDA had a mean age of $38.7 \pm 21.9$ (SD) months ranging from 24 to 96 months. The mean weight was $497.5 \pm 65.5 \mathrm{~kg}$ (SD) with a range of 425 to $600 \mathrm{~kg}$. The duration of illness ranged from 1 to 7 days with a mean of $3.9 \pm 2.13$ days $(\mathrm{SD})$. All LDA cases were diagnosed after hearing classical resonant sounds (pings) on simultaneous auscultation and percussion of the left flank, especially over the last three ribs during clinical examination. In cows the abomasum was imaged with transabdominal ultrasonography over the left middle to upper third of the abdomen especially at the $11-12$ th intercostal space and no adhesions were detected.

One-step laparoscopic abomasopexy was successfully performed in all 10 cows. No abdominal organs were accidentally perforated during the entrance of the trocar and no major complications were encountered during surgery. During exploration of the abdominal cavity, the distended abomasum was observed between the rumen and the abdominal wall on the left side. No other pathological findings such as free fluid, adhesion or lesions were recorded. The median operation time, which was defined as the time required to insert the trocar and close the wound, was 46 minutes (range, 29 to $76 \mathrm{~min}$ ). The suture material was cut in some cases (cows 2, 4, and 8) by the lancet contained within the spieker during the placement of the suture in the right paramedian area. In these cases, this phase of the operation was repeated. This caused a prolongation of the operation time (mean $35 \mathrm{~min}$ ).

In the postoperative period, gastrointestinal motility was restored within hours after surgery. The demand for water and hay increased in the postoperative period. Only in one case (case no. 9) recurrence of LDA was observed on day 129. The animal was re-operated.
The macroscopic appearance of the site of fixation (the tissue under and around the rubber bottle cap) in all cows showed swelling with mild pain (inflammation) on day 28 . The swelling noticeably decreased on successive examination days and was replaced by scar tissue. There was no suture material at the fixation site examined on day 90 .

Ultrasonographic findings: The abomasal wall appeared as an echoic line. The ingesta were mostly homogeneous in all cows. In 9 of the 10 cows, abomasal contractions were normal (passive and slow movement) but an active movement of the abomasum was noticed in one case. A heterogeneous hypoechoic irregular-shaped mass (adhesion formation) was located between the abomasum and abdominal wall in all examinations (on day 28, 90 and 120).

On examination day 0 , the area of fixation was observed as a mild distorted subcutaneous tissue. The location of the toggle-pin was found at a central position within the abomasum in relation to the fixation area with the presence of a comet-tail artifact. In this area, the thickness values varied from 14.29 to $27.39 \mathrm{~mm}$; the average being $20.38 \pm$ $3.86 \mathrm{~mm}$ (mean $\pm \mathrm{SD})$.

On examination day 28 , the toggle was visible in all cows as a hyperechoic object with a comet-tail artifact but the location was different. The toggle-pin position changed cranially or caudally from the fixation area. The thickness values were 16.90 to $30.10 \mathrm{~mm}$; the average being $22.68 \pm$ $3.75 \mathrm{~mm}$ (mean $\pm \mathrm{SD})$ (Figure 1$)$.

Figure 1. A transverse (medial-lateral) ultrasound image on day 28 postoperatively (case 6 ). The toggle-pin ( $\searrow$ ) presenting the characteristic feature of a comet-tail shadowing artifact $(\swarrow)$. (D): the distance between the abdominal wall and the toggle-pin, (I) : Abomasum wall.

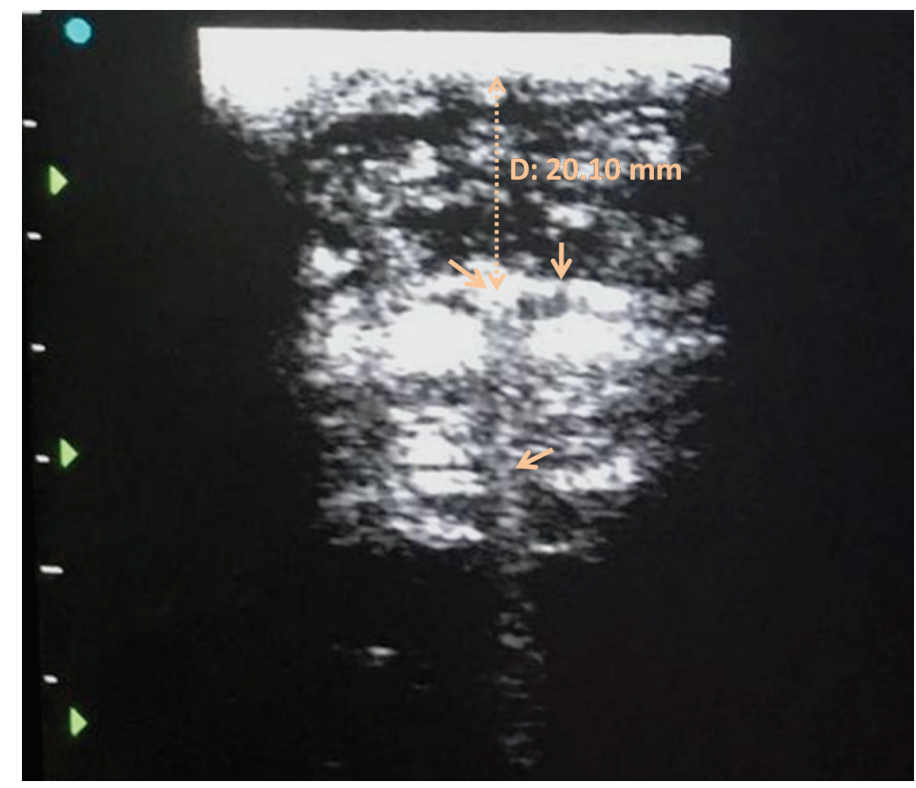


Figure 2. A longitudinal (cranial-caudal) ultrasound picture on day 120 postoperatively (case 10 ) presenting irregular shaped adhesion site $(\swarrow)$ which a hypoechoic area with small hyperechoic spots $(\searrow$ ), the abomasum wall (I).

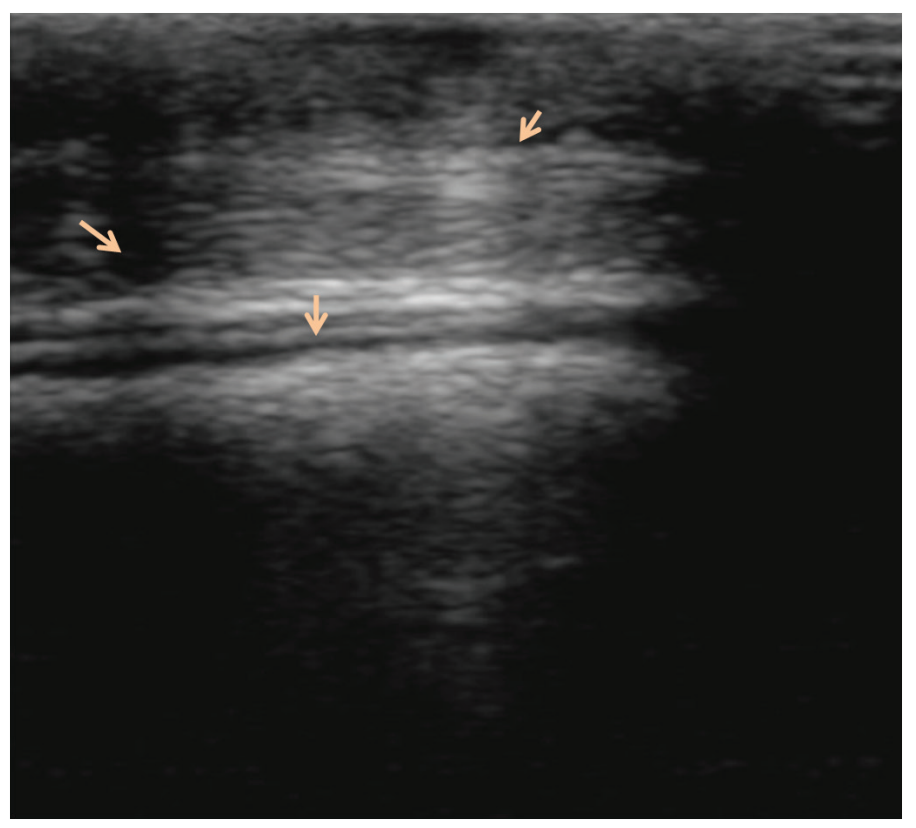

On examination day 90, the toggle-pin was not evident in ultrasound images in all cattle. The thickness values decreased in comparison with the earlier period and were measured as 12.63-27.87 $\mathrm{mm}$, the average being $21.85 \pm$ $4.23 \mathrm{~mm}$ (mean $\pm \mathrm{SD})$.

On examination day 120, the thickness values varied from 19.91 to $27.70 \mathrm{~mm}$; the average was $21.91 \pm 2.54 \mathrm{~mm}$ (mean $\pm \mathrm{SD})$. On the ultrasound image, there was a hypoechoic area with small hyperechoic spots (Figure 2).

A significant increase $(\mathrm{p}<0.05)$ was observed regarding the adhesion thickness from day 0 and 28 , and tended to decrease afterwards $(\mathrm{p}>0.05)$ (Table 1$)$.

Table 1. Ultrasonographic measurement values taken on different days of examination

\begin{tabular}{|c|c|}
\hline Days of examination & $\begin{array}{c}\text { Ultrasonographic measurement values (mm) } \\
\text { (Mean } \pm \text { Standard Deviation) }\end{array}$ \\
\hline 0 & $20.47+1.10^{\mathrm{a}}$ \\
\hline 28 & $22.82+1.13^{\mathrm{bc}}$ \\
\hline 90 & $22.34+0.90^{\mathrm{ac}}$ \\
\hline 120 & $21.92+0.90^{\mathrm{ac}}$ \\
\hline
\end{tabular}

p value: $0-90$ : $\mathrm{p}<0.080 ; 28-120$ : $\mathrm{p}<0.057 ; 90-120$ : $\mathrm{p}<0.066$

\section{Discussion and Conclusion}

One-step LA has been considered an advancement of the two-step laparoscopic technique, and is charecterized by the ventral fixation of a toggle suture by using a spieker. ${ }^{16}$ Our results show that one-step laparoscopic abomasopexy technique is advantageous in many ways, with shorter surgery time and faster postoperative recovery and characterized by higher food intake and lower incidence of wound complications. Similar results have been reported in the literature. ${ }^{6,12,13,16}$ The average surgical time in our study was higher than that reported in the literature (46 min). 4,6,16 This difference can be tarib uted to the number of cases in which the suture material was cut by the lancet contained within the spieker during the withdrawal of the spieker from the abdominal wall in this study (30\%), which increased the surgical time. The lower experience of the surgeons in this study could also have contributed to the increased surgical time. Similarly, Perotta et al. (2017) reported that the toggle thread was cut off by the trocar tip in one cow $(4.76 \%)$.

The rates of recurrence after one-step laparoscopic abomasopexy were reported between $1.97 \%$ and $9.52 \% .6,16$ In this study, one cow showed recurrence (10\%) of displacement on day 129 after surgery because of a lack of adhesion. The animal was re-operated. However, recurrence was not observed in other cows during the subsequent lactation period.

The success of any operation to correct a displaced abomasum depends on the formation of an adhesion to hold the abomasum in position. ${ }^{7}$ Abomasopexy and manipulations in the abdominal cavity cause adhesion formation at the site of operation. ${ }^{19}$ Only a few authors reported follow-up data for the assessment of adhesions of the abomasum to the body wall after laparoscopic abomasopexy. ${ }^{1,3,18}$ In these studies, the presence or absence of adhesions, as well as their appearance at the site of the abomasopexy, were confirmed by laparoscopic visualization or necropsy find ings. ${ }^{3,18}$ In only one study, ultrasonography was performed for the follow-up of adhesions in the postoperative period of two-step laparoscopic abomasopexy. ${ }^{1}$ To our knowledge, there is no other study in the literature about ultrasound follow-up of adhesions after one-step laparoscopic abomasopexy for the correction of LDA.

Ultrasonography provides reliable information concerning the abomasum, its contents and the condition of its wall and various developments of adhesion-fibrous tissue formation in adjacent structures. $^{1,15}$ The adhesion-fibrous tissue area can be characterized and manifested as echogenic deposits and also as echogenic constricting bands or high-level echoes, as suggested by researchers. ${ }^{17}$ Ultra-sonographic images of the toggle-pin show typical artefacts (comettail artifact) because of its metal structural nature. ${ }^{10}$ In this study, ultrasonographic examination was performed in standing position by a $5 \mathrm{MHz}$ linear transducer as suggested by other researchers. ${ }^{1,5,15}$ The abdominal wall, abomasum content and wall of the abomasum, and 
toggle pin were easily examined in this way.

Al-Bayati (2011) was able to detect the toggle-pin in ultrasonographic controls even on the $180^{\text {th }}$ and $270^{\text {th }}$ days after o peration and also identified oval; roundshaped hypoechoic adhesions between abomasal and abdominal walls. In our study, the toggle-pin was detectable ultrasonographically on days 0 and 28, but could not be determined in any case on day 90 . On the 90th day of the cases, there was no suture material on the fixation line. It was considered that the suture material had been continuously in contact with the abomasal content and therefore its strength was reduced and the threads were broken by organ movements. Ultrasonographically, the adhesion area showed a heterogeneous hypoechoic irregular-shaped mass between the abomasum and abdominal wall on examinations on day 28, 90 and 120. The adhesion thickness tended to decrease from day 28 to day 120 . Similarly, in the study of Al-Bayati (2011), highest adhesion values were seen four weeks postoperatively and then decreased over time.

The localized inflammation at the site of fixation which was seen one month postoperatively may be due to the leakage of abomasal content into the wound area1 or as a result of the normal defense mechanism against the suture material. ${ }^{8}$ In our study, the swelling at the fixation site noticeably decreased on day 90 and was replaced by scar tissue. This decrease in tissue reaction could be interpreted by the absence of suture material.

Although laparoscopic techniques have been widely accepted in clinical practice for treatment of LDA, information about the strength and size of adhesions required to prevent recurrence after LA is still inadequate and further research is required. To the best of our knowledge, this is the first report describing ultrasonographic follow-up of adhesions after one-step laparoscopic abomasopexy for correction of LDA. According to our findings, ultrasono-graphic examination provides useful information regarding adhesion formation at the abomasopexy site. Long follow-up studies are thought to be necessary for the evaluation of the size, thickness and quality of the adhesion formation in the postoperative period.

\section{Acknowledgements}

This study was financially supported by the Scientific Re-search Projects Unit of Uludag University by the project number KUAP(V)-2014/8.
The authors would like to thank Hakan UZUN School of Foreign Languages, and İ. Taci CANGUL from Uudag University, Faculty of Veterinary Medicine, Pathology Department for linguistic reading of this manuscript.

\section{Conflict of Interest Statement}

The authors declared that they had no conflict of interest.

\section{References}

1. Al-Bayati A. Development of abdominal adhesions after laparoscopic abomasopexy. (PhD Thesis) College of Veterinary Medicine, Justus-Liebig University Giessen, 2011:38-82.

2. Babkine M, Desrochers A. Laparoscopic Surgery in Adult Cattle. Vet Clin Food Anim. 2005;21:251-279.

3. Babkine M, Desrochers A, Bouré L, Hélie P. Ventral laparoscopic abomasopexy on adult cows. Can Vet Journal. 2006;47:343-348.

4. Barisani C. Evoluzione della tecnica di Janowitz per la risoluzione della dislocazione abomasale sinistra secondo Barisani. Summa 2004;5:35-39.

5. Braun U. Ultrasonography in gastrointestinal disease in cattle. Vet Journal. 2003;166:112-124.

6. Christiansen K. Laparoskopisch kontrollierte Operation des nach links verlagerten Labmagens (Janowitz-Operation) ohne Ablegen des Patienten. Tierarztl Prax. 2004;32:118-121.

7. Connell J. Four Methods of Surgical Correction of Abomasal Displacement in the Cow. Iowa State University Vet. 1976;38:21-24.

8. Fecteau G. Peritonitis in the Ruminant. In: Large Animal Internal Medicine. 4th ed. Mosby, Elsevier, St Louis, 2008:850-855.

9. Freick M, Sieber I, Endtmann A, Passarge U, Passarge O. Laparoscopic reposition of the displaced abomasum in a dairy herd in Saxony (Germany) - a case series (Article in German). Tierärztliche Umschau. 2013;68: $311-321$.

10. Grechenig W, Clement HG, Fellinger M, Schleifer $\mathrm{P}$, Tesch PN. Ultrasound imaging and localization of metal implants. A clinical study. Unfallchirurg. 1996;22:117-123.

11. Janowitz H. Laparoscopic reposition and fixation of the left displaced abomasum in cattle. Tierarztl Prax Ausg G Grosstiere Nutztiere. 1998;26(6):308-313.

12. Mulon PY, Babkine M, Desrochers A. Ventral laparoscopic abomasopexy in 18 cattle with displaced abomasum. Vet Surg. 2006;33:347-355.

13. Newman KD, Anderson DE, Silveira F. One-step laparoscopic abomasopexy for correction of left-sided displacement of the abomasum in dairy cows. J Am Vet Med Assoc. 2005;227:1142-1147. 
14. Newman KD, Harvey D, Roy JP. Minimally invasive field abomasopexy techniques for correction and fixation of left displacement of the abomasum in dairy cows. Vet Clin N Am-Food A. Philadelphia, 2008;24(2):359-382.

15. Ok M, Arıcan M, Turgut K. Ultrasonographic findings in cows with left and right displacement of abomasum. Revue Méd Vét. 2002;15:15-18.

16. Perotta JH, Ollhoff RD, Naylor Lisboa JA, de Barros Filho IR. One-step laparoscopy for the correction of left abomasal displacement in high-yielding Holstein dairy cows. Semina: Ciências Agrárias. 2017;38:13131322.

17. Schmidt G. Thieme Clinical Companions: Ultrasound. 3rd ed. Stuttgart, New York, Georg Thieme Verlag; 2007.

18. Thomas KL, Wilson DG, Bracamonte Jl, Carmalt JL, Luby CD. Quality of Adhesions After Sutured Paramedian vs. Laparoscopic Toggle Abomasopexy in an Ovine Model. Vet Surg. 2016;45:488-493.

19. Zografos GC, Simeonidis KM, Messaris EG, Parasi AS, Sotiriou HG, Dontas IA. Adhesion formation and intraperitoneal catheters: histologic findings in a rat model. Fertil Steril. 2005;83:516-518. 